\title{
Digitalization of Investment-Innovative Activities of the Trade Business Entities in Network IT-System
}

\author{
NATALIA V. TRUSOVA ${ }^{1}$, DENYS V. YEREMENKO ${ }^{2}$, SERHII V. KARMAN ${ }^{3}$, IRYNA V. \\ KOLOKOLCHYKOVA ${ }^{4}$, SVITLANA V. SKRYPNYK ${ }^{5}$ \\ ${ }^{1}$ Department of Finance, Banking and Insurance, DMYTRO MOTORNYI TAVRIA STATE AGROTECHNOLOGICAL \\ UNIVERSITY, UKRAINE. E-mail: n.trusova@tanu.pro \\ 2,3,4 Department of Business Consulting and International Tourism, DMYTRO MOTORNYI TAVRIA STATE \\ AGROTECHNOLOGICAL UNIVERSITY, UKRAINE. ${ }^{2} E-m a i l:$ d.yeremenko@uohk.com.cn; \\ ${ }^{3} \mathrm{E}$-mail: skarman@uohk.com.cn; ${ }^{4} \mathrm{E}$-mail: kolokolchykova7214@tanu.pro \\ ${ }^{5}$ Department of Accounting and Taxation, KHERSON STATE AGRARIAN AND ECONOMIC UNIVERSITY, UKRAINE. \\ E-mail: sskrypnyk@tanu.pro
}

\begin{abstract}
The problem of digital business transformation through innovative development in the country, which affects the transformation of business structures, including trade, remains underdeveloped, which requires further scientific, methodological, practical research and justification. The priority of this study is to develop a systemintegrated methodology and practical recommendations for building a model of digitization of investmentinnovative activities of the trade entities by transforming the architecture of the business system into an ITsystem, which demonstrates improving network interaction in a competitive environment. The article considers the digitalization of investment-innovative activities of the trade entities in the network IT system. The systemintegrated methodology is implemented and practical recommendations are offered to build a model of digitalization of investment-innovative activities of the trade entities by transforming the architecture of the business system into an IT system, which demonstrates the efficiency of network interaction in a competitive environment. The block diagram of the activation of Digital-strategy of digitalization of investment-innovative development of business in economy is presented. A block system for evaluating the digitalization of investmentinnovative activities of the trade entities in the network IT system is proposed. Indicators of digitalization of investment-innovative activities of the trade entities in the network IT system are grouped according to the components of the balanced scorecard (CFS). The architectural structure of the integrated indicator of the zonal level of digitalization of investment-innovative activities of the trade entities in the network IT system is substantiated. The coordinates of the vector-standard of zonal digitization of investment-innovative activities of the trade entities in the network IT system of Ukraine are determined.
\end{abstract}

Keywords: business processes, IT-outsourcing, global market, technologies, zonal level.

JEL Classification: L24, L81, L86, M15. 


\section{Introduction}

The processes taking place today in the world economic space are characterized by a significant intertwining of the interests of global economic and political players. Because of the struggle for markets and resources, more and more segments of the global market are under the influence of transnational corporations, which dictate their terms of cooperation with other, less powerful economic entities. The latter, in order to maintain their place in the market, have to make more and more efforts, promptly responding to new challenges and finding new ways to form a competitive advantage, in particular, in rather narrow niches. However, the growing globalization of the economic space leads to increased competition not only at the level of individual businesses, but also at the level of national economies. Understanding modern economic processes, it should be noted that they are fully defined by economic theory through the prism of a market economy, and therefore do not allow to determine the historical perspective of human society in general. That is, to win in a competitive environment with standard tools means further deterioration of the economy. At the same time, the globalization of economic processes has the features of instability, which significantly complicates the development of business in the country. Therefore, this situation can be corrected only through the growth of "creative and information culture", which symbolizes the understanding of other areas of investment-innovative business development and its transition to a new form - the digital economy.

Digital technologies in the modern world create fundamentally new opportunities for building interaction between the state, business and the population, eliminating long chains of intermediaries and accelerating the conduct of various transactions and operations. Such factors come to the fore due to the rapid development of information technology and globalization of the economy, which offer fundamentally new concepts of consumption and open up additional potential for the development of new markets and innovative developments. However, at present, the digitalization of the economy in underdeveloped countries is actually narrowed to the development of communication and information networks, as the digital infrastructure in such countries is underdeveloped. It is obvious that in such conditions, firms, including tradeones, need to intensify investment-innovative development, so as not to lose global competitiveness and connection with their audience. The solution of this problem belongs to the type of complex multicriteria tasks, which actualizes the research in the perspective of theoretical and methodological, as well as the institutional base of business development in the digital economy.

Solving the problems of investment-innovative development of business in the context of organizational and legal functioning of the institutes of innovative-investment activity was discussed in the works of such scientists as C. Arkolakis (2018); B. Arthur (1989); T. Bochulia, P. Hrynko, M. Mukhina (2018); T. Davenport (1993); P. Drucker (1995); N. Foss and T. Saebi (2018); P. Garber (1996); F. Hayek (1948). The problems of formation of digital economy in the world, its influence on business transformation are investigated by the following scientists: G. Brandon (2017); S. Côté and C. Miners (2006); D. Cox and A. Stuart (1955); J. Daum (2002); D. Goleman (1995); G. Hamel and C. Prahalad (2005); N. Lane (1999); processes of formation of investment-innovative business model are discussed in the works of: E. Rogers (2002); A. Sorescu, R. Frambach, J. Singh, A. Rangaswamy and C. Bridges (2011); J. Sowa and J. Zachman (1992); D. Tapscott (1996); J. Zachman (1987); P. Zhu (2016); S.A. Davymuk et al. (2016); P. M. Hryhoruk (2013); B. Kulchytska and L.S. Predko (2018). However, despite significant scientific development, the problem of digital business transformation through innovative development in the country, which affects the transformation of business structures, including trade, remains underdeveloped, which requires further scientific, methodological, practical research and justification. The priority of this study is to develop a system-integrated methodology and practical recommendations for building a model of digitization of investment-innovative activities of the trade entities by transforming the architecture of the business system into an IT-system, which demonstrates improving network interaction in a competitive environment. 


\section{Materials and Methods}

Activation of investment-innovative activities of business provides conditions for stable growth of the scale of network interaction of enterprises to reduce the cost of innovative goods (services). The development of investment-innovative business is formed on the basis of assessment and analysis of its real and potential technological level, modern IT-systems, customer analytics, number of business processes, knowledge-intensive products, increasing the level of innovation culture aimed at commercializing accumulated knowledge in ensuring increased competitiveness. Digitization of investment-innovative activities of business reflects a complex dynamic intensive development of business entities, which is quantitatively characterized by the ratio of changes in the effectiveness of their interaction in various sectors of the economy and the rate of change of resource costs involved in investment-innovative process (Davymuk et al., 2016; Vyshnevskyi et al., 2021).

Activation of digital technologies in investment-innovative activities of business entities reflects the intensity of their efforts to attract available resources in the investment-innovative process to achieve the optimal level of realization of their interests, resulting in experience, knowledge, professional competencies, intuition, developing through emotional intelligence, which depends on the intellectual potential of staff in the business. Thus, transition of digital business systems to IT-systems for effective synchronization of information and communication technologies and intellectualization of the capital in economy allows receiving effect from realization of Digital strategy of investment-innovative development of business (Figure 1).

Figure 1 Block diagram of the activation of Digital-strategy of digitalization of investment-innovative business development in the economy

Investment-innovative transformation of business into an IT-system and digitalization of the economy

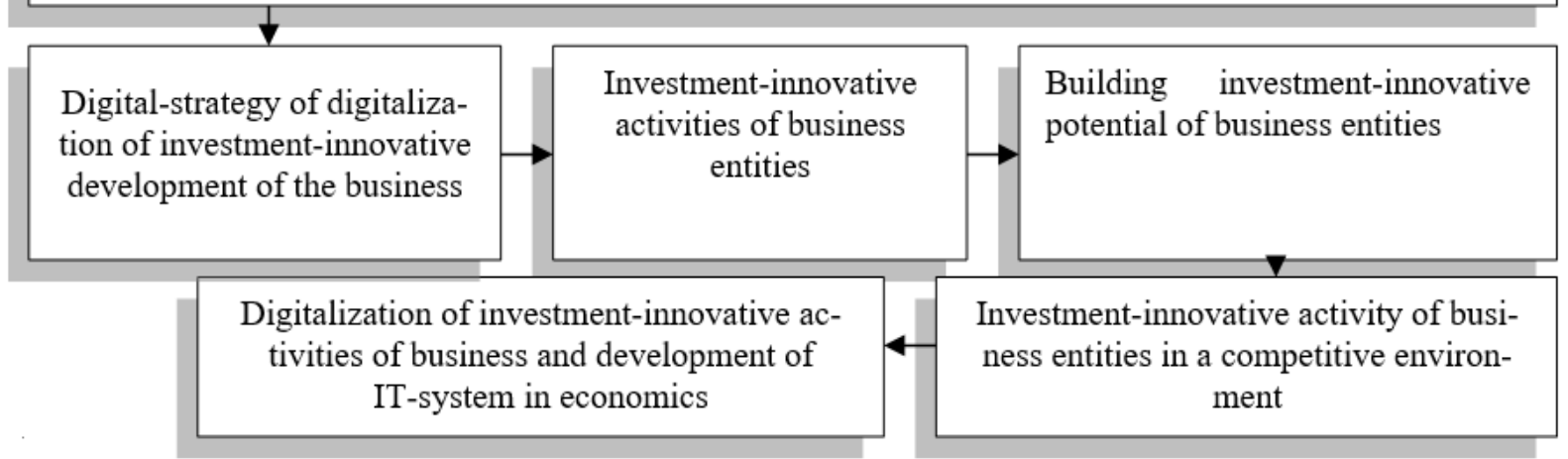

Source: built by the authors according to data Davymuk et al., 2016; Digital globalization..., 2017.

The digitalization of investment-innovative activities of business and the development of IT-systems in the economy is determined by the factors that generate and activate the network interaction of entities in a competitive environment that promote or, conversely, hinder the implementation of innovations. The authors propose to divide the system of factors into blocks to assess the digitalization of investment-innovative activities of the business (Digital single..., 2017; Digital globalization..., 2017; Oklander et al., 2021):

1. evaluation and performance block, which includes factors of general assessment of investmentinnovative activities of business entities and determines their market value: return on investment (innovation), sales of investment-innovative goods (services), coefficients of innovation costs, profitability ratios, R\&D stages, experimental and test works, main and auxiliary production, marketing, etc. This block also includes resource potential, which generates the optimal allocation of resources in the investment-innovative activities of the entities;

2. organizational-structural block, which includes factors of organizational structure of business entities and determines the levels of work efficiency: complexity of architecture configuration, composition and quality of division of labor, quality of internal and external vertical and horizontal communication channels, distribution of rights and responsibilities, staff motivation, 
etc. Indicators for assessing the effectiveness of the business process between business entities are quantitative and qualitative, obtained by experts;

3. information technology unit that ensures the transition of the business system to the IT system through the use of advanced software and information technologies: staffing factors of computers and software, the level of computerization of business processes, software consistency (level of unification), the degree development of the internal network, integration into the Internet, the level of presence of business entities in social networks, the volume of products sold virtually, the effectiveness of work through outsourcing, etc.

Structuring the format of those factors that allow qualitative characterization of the potential of investment-innovative activities of business entities in the context of digitalization of the economy should be developed based on the priority of key factors of IT development and criteria for selecting the highest priority indicators. The authors offer balanced system indicators (BSI) to assess the digitalization of investment-innovative activities of the business (Figure 2), which are the most acceptable for enhancing the competitiveness of business processes in the economy.

Figure 2 Block system for evaluating the digitalization of investment-innovative activities of trade entities in the network IT system

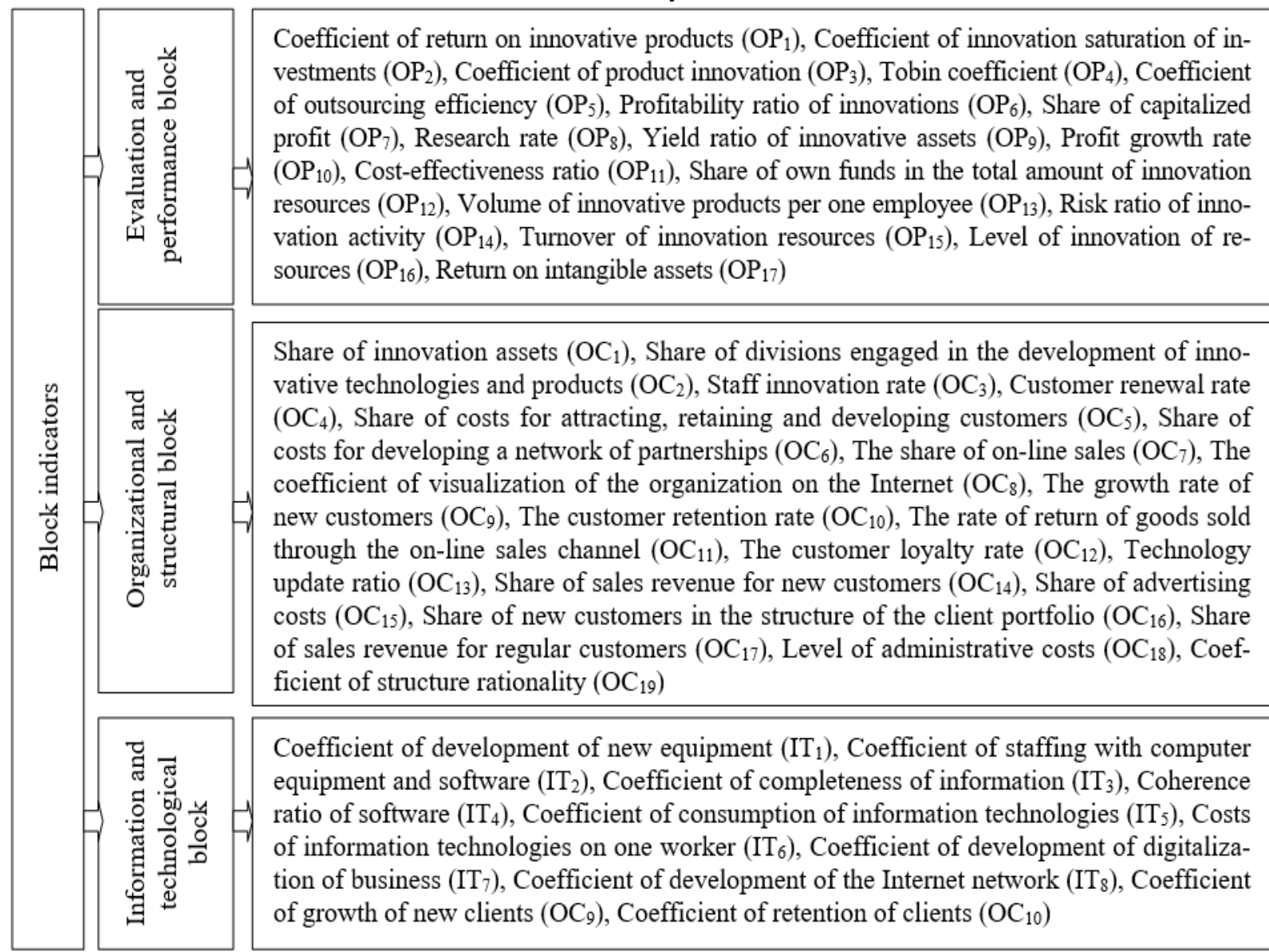

Source: developed by the authors.

We propose to combine the tools of formation of BSI of digitalization of investment-innovative activity of business and development of IT-system in economy on such components: "Financial activity", "Counterparties", "Internal business processes" (Table 1). It should be noted that among the traditionally used standardized indicators (coefficient of innovation saturation; coefficient of sales volume virtually, the economic effect of innovation; profitability of regular customers, etc.), business processes of various sectors of the economy use floating indicators, which relate to the level of visualization (coefficient of innovation progress, brand awareness, etc.) and the quality of digitalization of the economy through the IT-system. 
Digitalization of investment-innovative activities of the trade business entities in network IT-system

Table 1 Grouping of indicators of digitalization of investment-innovative activities of trade entities in the network IT-system by components of the BSI

\begin{tabular}{|c|c|c|}
\hline $\begin{array}{l}\text { Block of } \\
\text { indicators }\end{array}$ & Legend & Indicator \\
\hline \multirow{4}{*}{$\begin{array}{l}\text { Financial } \\
\text { activity }\end{array}$} & Strengthening innovation potential & $\mathrm{OP}_{2} ; \mathrm{OP}_{9} ; \mathrm{OP}_{15} ; \mathrm{OP}_{16} ; \mathrm{OP}_{17}$ \\
\hline & $\begin{array}{l}\text { The growth of the market value of the } \\
\text { organization }\end{array}$ & $\mathrm{OP}_{4} ; \mathrm{OP}_{7}$ \\
\hline & Ensuring financial stability & $\mathrm{OP}_{6} ; \mathrm{OP}_{10} ; \mathrm{OP}_{12} ; \mathrm{OP}_{14}$ \\
\hline & Improving the efficiency of cost management & $\mathrm{OP}_{1} ; \mathrm{OP}_{5} ; \mathrm{OP}_{8} ; \mathrm{OP}_{11}$ \\
\hline \multirow{3}{*}{ Counterparties } & Attracting new and retaining existing customers & $\begin{array}{l}\mathrm{OC}_{4} ; \mathrm{OC}_{5} ; \mathrm{OC}_{9} ; \mathrm{OC}_{10} ; \mathrm{OC}_{14} \\
\mathrm{OC}_{16} ; \mathrm{OC}_{17}\end{array}$ \\
\hline & Improving customer service & $\mathrm{OC}_{7} ; \mathrm{OC}_{8} ; \mathrm{OC}_{11} ; \mathrm{OC}_{12}$ \\
\hline & Improving partnerships & $\mathrm{OC}_{6} ; \mathrm{OC}_{15}$ \\
\hline \multirow{4}{*}{$\begin{array}{c}\text { Internal } \\
\text { business } \\
\text { processes }\end{array}$} & $\begin{array}{l}\text { Intensification of work on the sale of innovative } \\
\text { products }\end{array}$ & $\mathrm{OP}_{3} ; \mathrm{OP}_{13}$ \\
\hline & $\begin{array}{l}\text { Improving the organizational structure of } \\
\text { management }\end{array}$ & $\mathrm{OC}_{2} ; \mathrm{OC}_{18} ; \mathrm{OC}_{19}$ \\
\hline & $\begin{array}{l}\text { Improving the technical level of the production } \\
\text { process }\end{array}$ & $\mathrm{OC}_{1} ; \mathrm{OC}_{13} ; \mathrm{IT}_{1} ; \mathrm{IT}_{2}$ \\
\hline & Improving the efficiency of informatization & $\mathrm{IT}_{3} ; \mathrm{IT}_{4} ; \mathrm{IT}_{5} ; \mathrm{IT}_{6} ; \mathrm{IT} 7 ; \mathrm{IT}_{8}$ \\
\hline
\end{tabular}

Source: developed by the authors.

To determine the level of achievement of a certain effect from the introduction of the IT system in the economy, the authors use test-type indicators, which in a balanced scorecard take into account the intermediate results of the forecast period. Thus, T. Davenport (1993) and E. Rogers (2002), divide the indicators into preventive and delayed, which balance the causal chain of intermediate and forecast investment-innovative process in the existing business system and its transformation into an IT system that directly related to business communication. Accordingly, these processes activate information technology in business to increase customer focus in order to ensure sales growth through additional established channels for the sale of goods on the Internet. However, in the network interaction of business entities, priority is given to processes related to the supply of goods, products and services through intermediaries. This allows assessing the degree of dependence of business structures (enterprises) on contractors. To address the issue of assessing the level of digitalization of investment-innovative activities of business and IT-system development, as well as the impact of recommended factors on the economy as a whole, the authors propose to use a system-integrated method that allows identifying multifactor indicators, which reflect the relationship between the blocks of BSI and their components, which are subject to the intermediate and projected business process.

We propose to determine the level of digitalization of investment-innovative activities of business and IT-system development by an integrated indicator, which embodies a conditional numerical measure of latent quality of business processes in the economy while ensuring in formativeness of both financial and nonfinancial factors (formula (1)) (Sorescu et al., 2011):

$$
I_{p}=\sum w_{k} I_{k}
$$

where, $I_{p}$ - an integrated indicator of the level of digitalization of investment-innovative activities of business and development of the IT-system; $I_{k}$ - group integrated indicator of assessment of the $k$ th component of BSI ("Financial activity", "Counterparties", "Internal business processes"), which form the level of digitalization of investment-innovative activities of business and IT-system development; $w_{k}$-the weight of the assessment indicators of the $k$-th component of the BSI, which form the level of digitalization of investment-innovative activities of business and IT-system development.

For the architectural construction of the integrated indicator the systematic formation of the initial information array and the goals of the integrated assessment of the zonal level of digitalization of investment-innovative activities of the trade entities in the network IT-system are systematized (Table 2). Thus, group integrated indicators are considered as synthetic (aggregate) results of assessment of 
a set of factors, the change of which indicates the level of activation of intermediate and projected business processes to achieve the effect of investment and innovation in network interaction of different business entities which ensure functioning of the country's economy.

Table 2 Architectural structure of the integrated indicator of the zonal level of digitization of investment-innovative

\begin{tabular}{|c|c|}
\hline $\begin{array}{l}\text { Direction of } \\
\text { assessment of the } \\
\text { integrated indicator }\end{array}$ & Characteristics of the original information array \\
\hline Aggregated & $\begin{array}{l}\text { The initial data represents quantitative measurement indicators, which are } \\
\text { displayed by an object-property matrix. The generalized indicator is } \\
\text { calculated by aggregation of initial indicators with approximation of structure } \\
\text { of relations between objects }\end{array}$ \\
\hline Criterial & $\begin{array}{l}\text { The initial indicators are criteria; aggregation is carried out by grouping } \\
\text { criteria }\end{array}$ \\
\hline Approximating & The initial data is a matrix of symmetric binary relations between alternatives \\
\hline Discriminant & $\begin{array}{l}\text { The initial data is presented in the form of an "object-property", and there is } \\
\text { also some given structure that defines the relationship between the } \\
\text { alternatives, dividing them into classes that do not intersect. In this case, the } \\
\text { problem of approximating this structure is also solved in order to be able to } \\
\text { classify new alternatives }\end{array}$ \\
\hline Expert-statistical & The initial data are the results of expert evaluation of alternatives \\
\hline Combined criterial & $\begin{array}{l}\text { The initial data is a correlation matrix calculated for all indicators, regardless } \\
\text { of their nature (provided that there is a corresponding relationship). } \\
\text { Aggregation is carried out on quantitative indicators; qualitative indicators } \\
\text { have a clarifying effect on the weights of the aggregation function }\end{array}$ \\
\hline
\end{tabular}
Source: grouped by authors according to data Hryhoruk, 2013; Kulchytska and Predko 2018.

Based on the proposed system of indicators presented in Table 1, the calculation of the group integrated indicator for the assessment of the k-th component of the BSI, which form the level of digitalization of investment-innovative activities of the business and the development of the IT-system is carried out according to formula (2) (Hryhoruk, 2013):

$$
I_{k}=\sqrt[m]{\Pi I_{j}}
$$

where, $I_{j}$ - an integrated indicator of the level of achievement of the $j$-th intermediate level of digitalization of investment-innovative activities of the business and the development of the IT-system in the projected business process; $m$ - the number of intermediate indicators for assessing the level of digitalization of investment-innovative activities of the business and the development of the IT-system in the projected business process, which correspond to the $k$-th component of the BSI.

We propose to calculate the values of intermediate integrated indicators with the help of taxonomic analysis, which allows summarizing the changes in several incomparable indicators in the form of an integrated normalized indicator with the interpretation of the obtained results. To identify the relative importance of factors of change of investment and innovation of business with the active introduction of digitalization and transformation of modern business system into IT-system, for a certain component of BSI, the authors propose to use the method of hierarchy analysis, also known as AHP (Analytical Hierarchy Process). The implementation of this method involves the formation of a matrix containing the results of expert comparisons of the components of the BSI. Using the scale of relative importance of T. Saati (Table 3), experts should determine how many times one component of the BSI is more important than another. According to this scale, the components of equal importance are matched to one, with a moderate advantage -3 , with a big advantage -5 , with a significant advantage -7 and with a very strong advantage -9 . Values $2,4,6,8$ are used as intermediates between two adjacent components. The method of model construction is widely used, according to which, the choice of priority system indicators of digitalization of investment-innovative activities of business and development of IT-systems in the economy allows to calculate them using 
pairwise comparisons. The method consists in decomposing the problem into simpler components and systematic prioritization of the evaluated components using even (pair) comparisons.

Table 3 Scale of pairwise comparisons

\begin{tabular}{|c|l|l|}
\hline $\begin{array}{c}\text { Relative } \\
\text { importance (points) } \\
a_{\mathrm{ij}}\end{array}$ & \multicolumn{1}{|c|}{ Definition } & \multicolumn{1}{|c|}{ Explanation } \\
\hline 1 & $\begin{array}{l}\text { Equally important } \\
\text { One element is somewhat more } \\
\text { important than the other }\end{array}$ & $\begin{array}{l}\text { Both elements have the same effect } \\
\text { Experience allows you to put one } \\
\text { element slightly higher than another }\end{array}$ \\
\hline 5 & Big advantage on over \\
\hline 7 & Significant advantage & $\begin{array}{l}\text { Unconditional advantage of one } \\
\text { the other }\end{array}$ \\
\hline $2,4,6,8$ & $\begin{array}{l}\text { One element is so important than the } \\
\text { other that it is practically significant }\end{array}$ \\
\hline $\begin{array}{l}\text { the other } \\
\text { Inverse values of of advantage of one over } \\
\text { the numbers given } \\
\text { above }\end{array}$ & $\begin{array}{l}\text { The obvious advantage is confirmed by } \\
\text { adjacent statements }\end{array}$ & $\begin{array}{l}\text { If after comparing one element with the second one of the above numbers (1-9) } \\
\text { is obtained, then due to the comparison of the second with the first we will have } \\
\text { the inverse value }\end{array}$ \\
\hline
\end{tabular}

Source: grouped by authors according to data Saati, 1993.

The construction of the priority vector includes several stages: the first stage is structuring the problem in the form of a hierarchy; the second stage is the construction of a matrix of pairwise comparisons of the elements of the second level of the hierarchy in relation to their influence on the first level of the hierarchy. The elements of the matrix are compared in pairs using the scale of pairwise comparisons of T. Saati (1993); the third stage is the determining the priorities of the elements of the second level of the hierarchy relative to the elements of the first level; the fourth stage is the assessment of the consistency of experts' opinions on the importance of the elements of the second level of the hierarchy; the fifth stage is the compilation of matrices of pairwise comparisons for the elements of the third level for each element of the second level of the hierarchy; the sixth stage is the assessment of the consistency of experts' opinions on the importance of the elements of the third level of the hierarchy; the seventh stage is the calculation of global priorities by linearly convolving the priorities of the elements in the hierarchy.

To implement the system-integrated method, the law of hierarchical continuity is introduced, according to which the elements of each level are compared in pairs relative to higher level elements, i.e. lower level elements (alternatives, variants) are compared in pairs in relation to criteria and criteria in relation to goal. The results of pairwise comparisons of elements at each level of the hierarchy by the method of T. Saati (1993) form an inversely symmetric matrix, the diagonal elements of which are equal to one. When filling the matrix, the property of inverse symmetry is used: symmetric cells are filled with inverse values. If the degree of preference of one element placed in a row $i$ and over an element located in column $j$ is expressed by a certain number $a_{i j}$, then the result of the inverse comparison is determined by the ratio:

$$
a_{i j}=1 / a_{i j}
$$

We note that the number $a_{i j}$ reflects the ratio of quantitative assessments of the quality of the $i$ th and $j$-th elements of the matrix:

$$
a_{i j}=w_{j} / w_{j}
$$

It is proposed to determine the vector of priorities by normalizing the main eigenvector of the matrix, as well as vectors of inversely symmetric matrices according to the following algorithm (Table 4): 
1. for each row of the matrix is determined by the sum of the elements. The result is normalized by dividing each sum by the sum of all elements. The sum of the normalized elements must be equal to one;

2. the elements of each column are summed and the inverse values of these sums are determined. The inverse values of the sums for each element are distributed to obtain normalized elements, the sum of which is equal to one;

3. normalized data for columns is determined by the ratio of the elements of each column to the sum of the elements of this column. The average normalized values for each line are calculated by the arithmetic mean formula, i.e. by dividing the sum of the elements for each line obtained by the number of line elements;

4. each row of the matrix is determined by multiplying the elements and is denoted by the root of the $n$-th degree, i.e. the geometric mean averaging is used.

A prerequisite for applying the hierarchy analysis method is to verify the consistency of the experts' assessments of the relative importance of the elements.

Table 4 Determination of the vector of priorities

\begin{tabular}{|c|c|c|c|c|c|c|}
\hline \multicolumn{5}{|c|}{ Matrix of pair wise comparisons } & \multirow[b]{2}{*}{$\begin{array}{l}\text { Calculation of estimates of the } \\
\text { eigenvector component }\end{array}$} & \multirow{2}{*}{$\begin{array}{l}\text { Rationing of results to } \\
\text { obtain } \\
\text { estimates of the vector } \\
\text { of priorities }\end{array}$} \\
\hline & $A_{1}$ & $A_{2}$ & $\ldots$ & $A_{n}$ & & \\
\hline $\mathrm{A}_{1}$ & $a_{11}$ & $a_{12}$ & $\ldots$ & $a_{1 n}$ & $\sqrt[n]{a_{11} \times a_{12} \times \ldots \times a_{1 n}}=v_{1}$ & $v_{i}=w_{1}$ \\
\hline $\mathrm{A}_{2}$ & $A_{21}$ & $A_{22}$ & $\ldots$ & $A_{2 n}$ & $\sqrt[n]{a_{21} \times a_{22} \times \ldots \times a_{2 n}}=v_{2}$ & $v_{i}=w_{2}$ \\
\hline$\ldots$ & $\ldots$ & $\ldots$ & $\ldots$ & $\ldots$ & $\ldots$ & $\ldots$ \\
\hline$A_{n}$ & $a_{n 1}$ & $A_{n 2}$ & $\ldots$ & $A_{n n}$ & $\sqrt[n]{a_{n 1} \times a_{n 2} \times \ldots \times a_{n n}}=v_{n}$ & $v_{n} / \sum v_{i}=w_{n}$ \\
\hline \multicolumn{5}{|c|}{ Total } & $\sum_{i=1} v_{i}$ & 1 \\
\hline
\end{tabular}

Source: grouped by authors according to data Saati, 1993.

The consistency of experts' opinions is checked using the index $(I Y)$ and the relative consistency indicator $(V Y)$ :

$$
I Y=\frac{\lambda \max -m}{m-1}
$$

where, $\lambda \max$ - the largest eigenvalue of the matrix; $m$ - the order of the matrix.

To find the maximum eigenvalue of the matrix according to the matrix of pairwise comparisons and the vector of local priorities, formula (4) is used:

$$
\lambda \max =\sum_{j=1}^{n} w_{j}\left(\sum_{i=1}^{n} a_{i j}\right),
$$

The calculation of the relative consistency index made by the value of the consistency index will be confirmed by the calculation of the relative consistency indicator $(V Y)$ :

$$
V Y=\frac{I Y}{S I Y}
$$

where, $S I Y$ - is the average value of the consistency index.

Due to the fact that the values of the integrated indicator vary from zero to one, to identify the level of digitalization of business investment-innovative activities in the economy, the authors propose the use of verbal-digital Harrington scale, which allows qualitative characterization of quantitative indicators. Thus, balancing the indicators of digitalization of investment-innovative activities of 
business and the development of IT-systems in the economy, determines the ability to balance their assessment in the forecast business process. This allows for the formation of its information tools, and the recommendations for assessing the level of digitization of investment-innovative activities of business and development of IT-systems in the economy are aimed at improving the quality of business communication with additional channels for selling goods on the Internet. The implementation of the proposed system-integrated methodology to assess the level of digitization of investment-innovative activities of business and IT-system development not only improves the efficiency of networking of entities in various fields and prioritizes their interests in business processes, but also influences investors' decisions on investing resources in the economy.

\section{Results and Discussion}

Fierce competition between the enterprises of the trade network in Ukraine leads to a change in their investment-innovative activities and the development of digitalization of business, due to the dynamic transformation of the modern business system and the introduction of the IT-system in the economy. Despite belonging to low-tech sectors of the economy, trade plays an important role in the development of innovation, acting as an intermediary between high-tech industries and consumers. At the same time, in the context of global integration and globalization, increasing the requirements for the quality of service and maintenance, trade networks are beginning to intensify investmentinnovative processes in order to increase the level of profitability and competitiveness of trade enterprises. And in this sense, investment-innovative activities of trade enterprises is to create a new product proposal for the implementation of existing developments in practice, taking into account the industry characteristics of major business processes that affect profits, productivity, improve competitiveness and cost optimization.

Digitalization of investment-innovative activities of trade enterprises allows adapting the mechanism of movement of goods at all stages of trade services to ensure high quality of the process of purchase and sale and implementation of online trade, strengthening customer orientation of the business system (Davymuk et al., 2016). The authors implement the recommended methodology for assessing the level of digitalization of investment-innovative activities of trade entities in the network ITsystem, in such areas as Forest-Steppe, Polissya and the Western region, as well as in the Steppe zone. The time interval of the study, which in authors ' opinion is justified, is three years (2018-2020), as rapid changes in the economy reflect the accelerated dynamics of the IT-system in the direction of stimulating and intensifying investment-innovative business processes. Selected trade entities in the IT network in the Forest-Steppe, Polissya and Western regions, as well as in the Steppe, operate in the same segment of the consumer market with identical areas of implementation of the Digital-strategy of investmentinnovative development of trade, have the same format, close range of goods sold, use identical customer service technologies, similar means of advertising, have Internet trade channels, etc. (Tables 5-7).

Table 5 Coordinates under the vector-standard of the "Financial activity" in the zonal digitization of investmentinnovative activities of trade entities in the network IT-system of Ukraine

\begin{tabular}{|c|c|}
\hline $\begin{array}{l}\text { Digital-strategy of } \\
\text { digitalization of investment- } \\
\text { innovative development of }\end{array}$ & $\begin{array}{c}\text { Zones of digitalization of investment-innovation activity of trade } \\
\text { business entities in the network IT-system of Ukraine }\end{array}$ \\
\hline $\begin{array}{l}\text { Increasing the market value of } \\
\text { the organization }\end{array}$ & $\begin{array}{c}\text { OP9 } \\
\begin{array}{l}\text { OFolissya and } \\
\text { Western region zone } \\
\text { Steppe zone }\end{array}\end{array}$ \\
\hline
\end{tabular}


Nataliav. Trusova, Denys V. Yeremenko, Serhii V. Karman, Iryna V. Kolokolchykova, Svitlana V. Skrypnyk

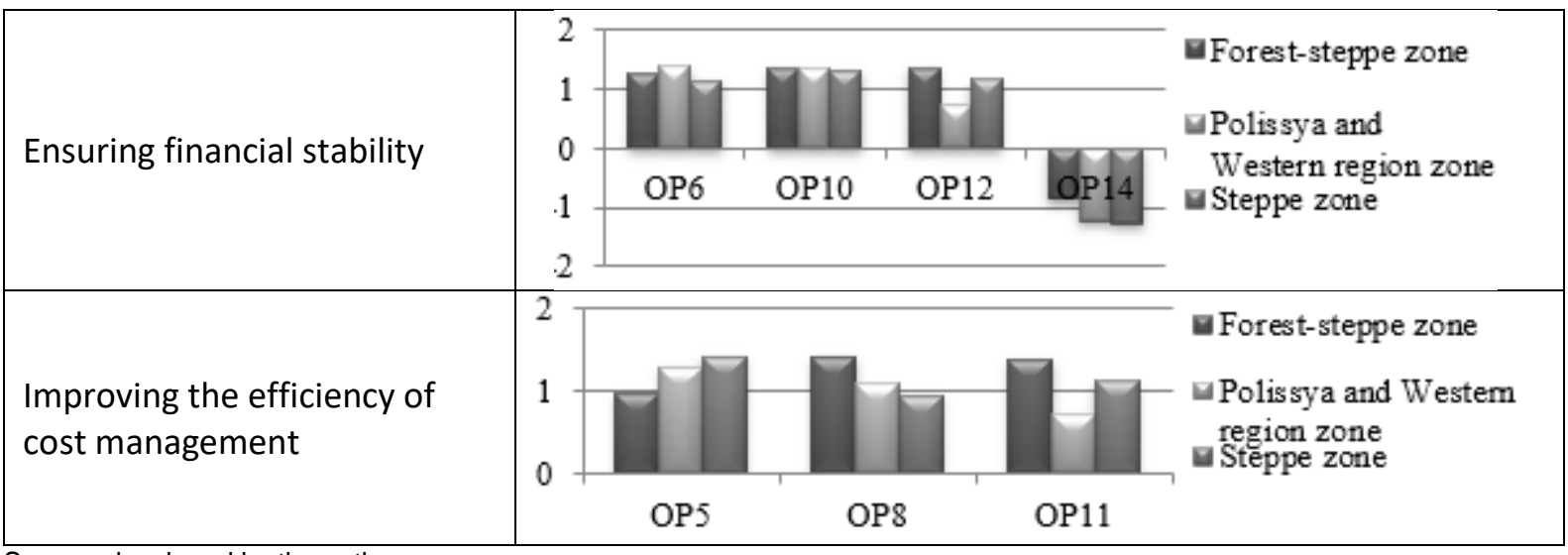

Source: developed by the authors.

Table 6 Coordinates under the vector-standard of the "Counterparties" in the zonal digitization of investmentinnovative activities of trade entities in the network IT-system of Ukraine

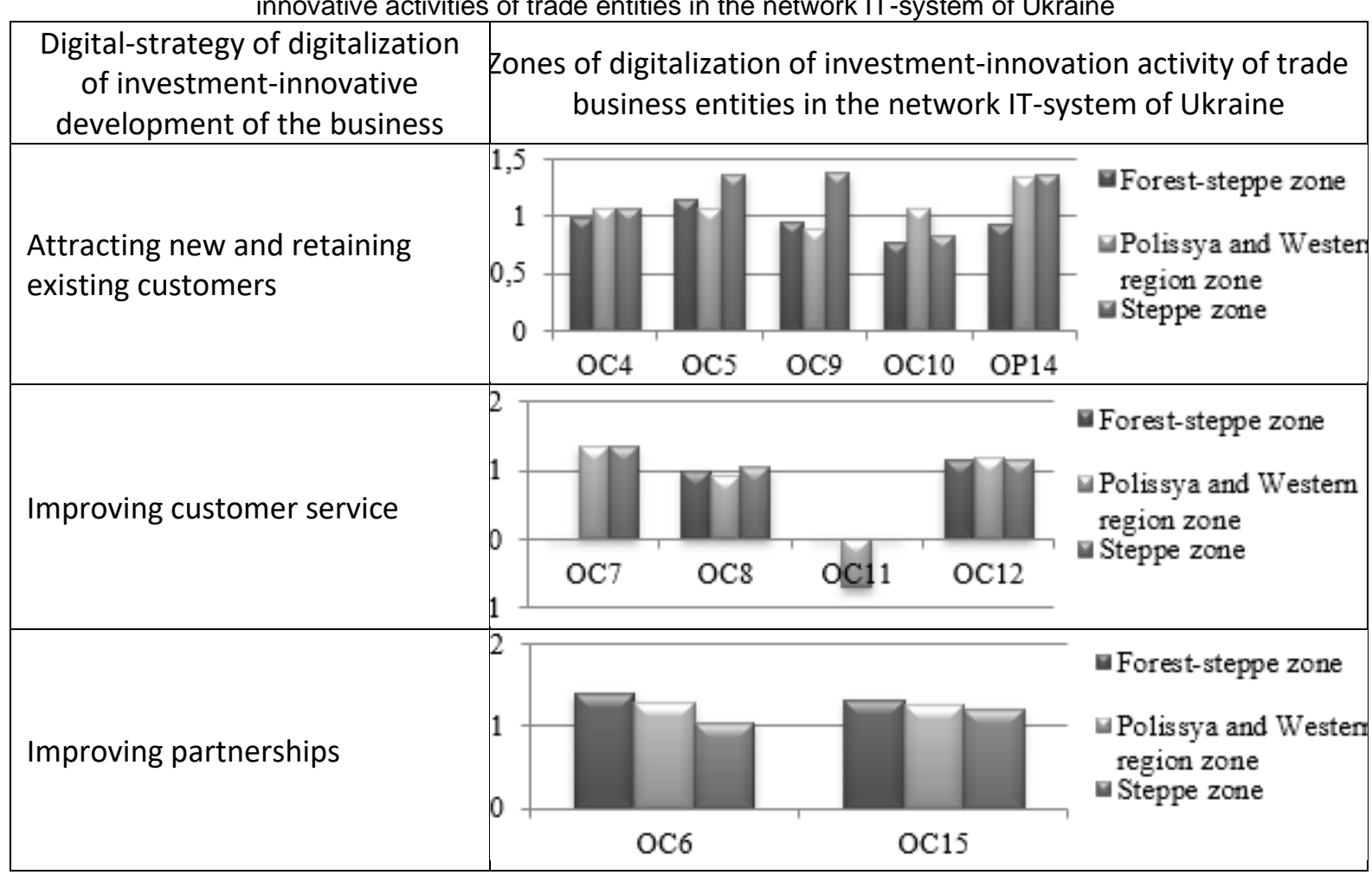

Source: developed by the authors.

Table 7 Coordinates under the vector-standard "Internal business processes" in the zonal digitization of investmentinnovative activities of trade entities in the network IT-system of Ukraine

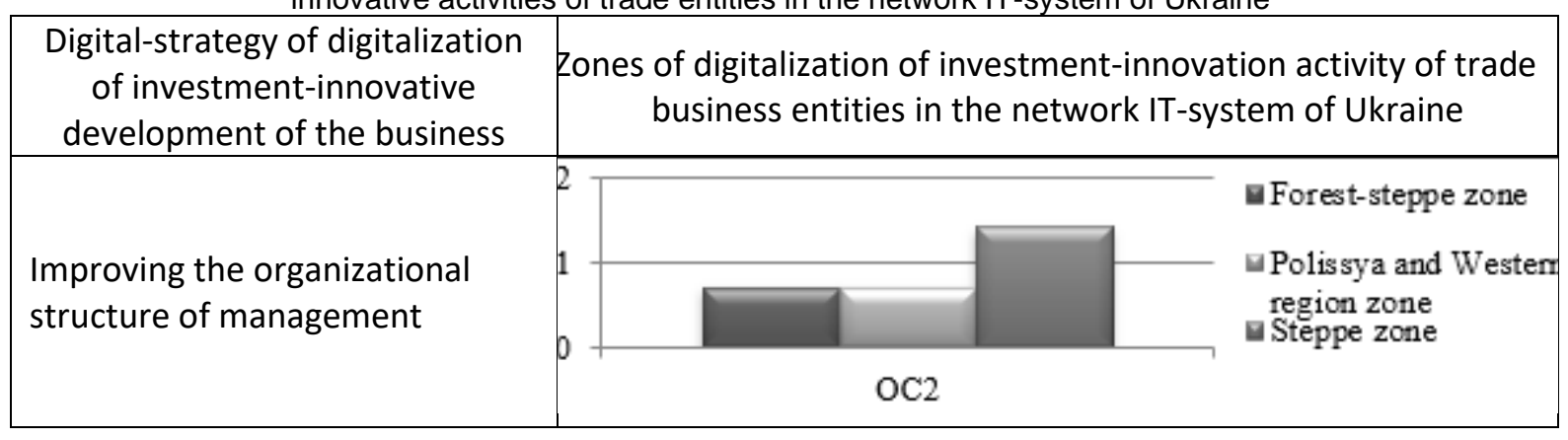




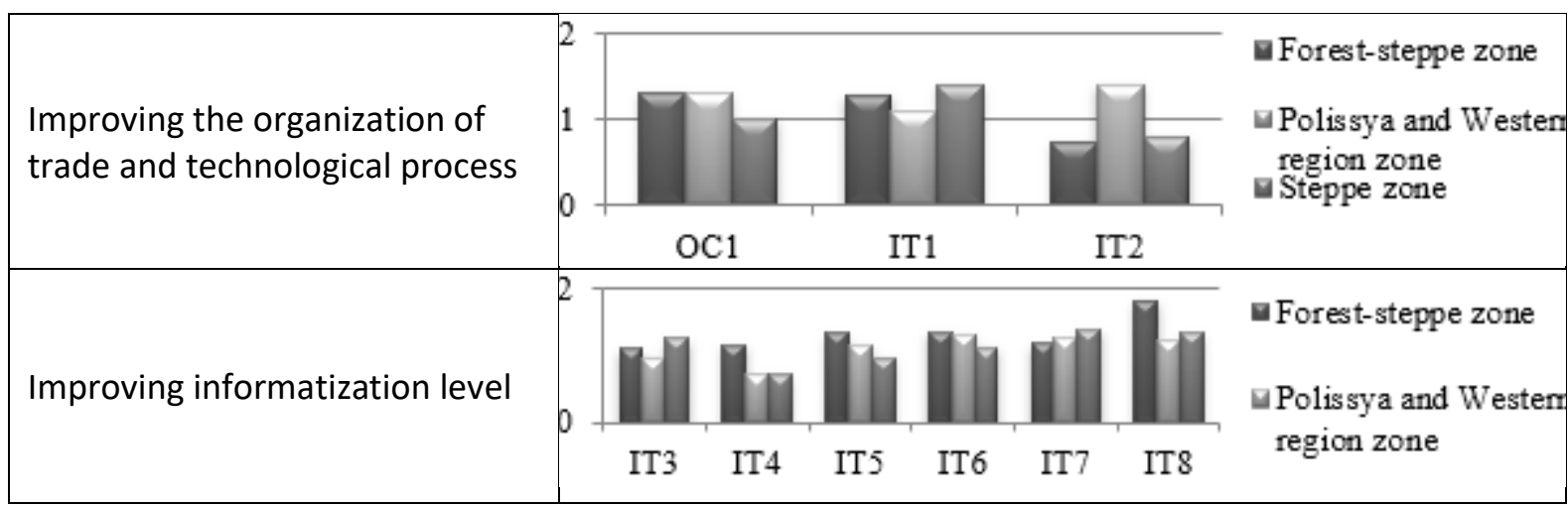

Source: developed by the authors.

Innovations of trade entities, which are aimed at developing relationships with various contractors, are evaluated on the indicators of attracting new and retaining existing customers, improving their service, improving partnerships. The activity of trade business entities in the direction of investmentinnovative changes in internal business processes is studied by indicators of the organizational structure of management, the level of security of innovative assets and the level of informatization. The intermediate integrated indicators of the level of digitalization of investment-innovative activity of trade business entities in the network of IT-system by the selected zones of Ukraine obtained as a result of taxonomic analysis are presented in Figures 3-11. Thus, when assessing the indicators that characterize the financial support of investment-innovative activity of trade entities, we can see the lack of a stable trend of their change and significant fluctuations within the zonal boundaries of trade enterprises. The highest level of growth of the market value of the organization is observed in the area of Polissya and the Western region in 2019 (IFA $A_{1}=0.849$ ), and the lowest - in the Forest-Steppe zone in 2020 (IFA $\left.A_{1}=0.265\right)$. The most financially stable was the activity of the subjects of the trade business zone of Polissya and the Western region (IFA $2=0.870$ ) in 2020, which is 0.643 points more than the subjects of network communication of the IT system of the Steppe zone, and 0.527 points higher than the level of 2019.

Figure 3. Integral level of digitalization of investment-innovative activity of trade business entities in the network IT-system of the Forest-Steppe zone of Ukraine under the vector-standard "Financial activity"

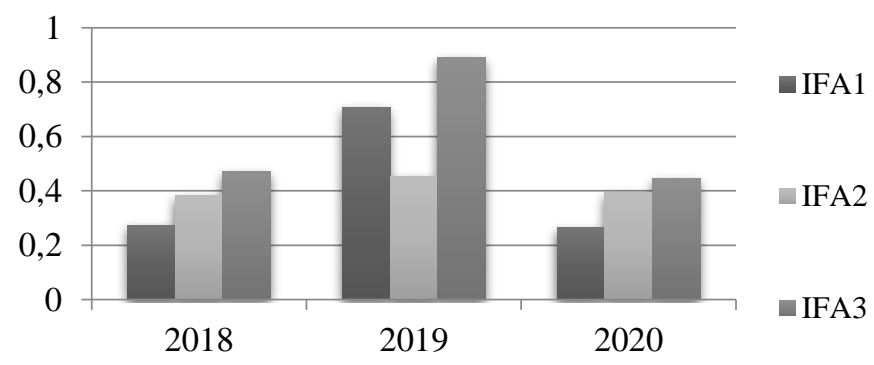

Source: calculated by the authors.

Note: IFA $_{1}$ - increase in the market value of trade entities; IFA 2 - growth of financial stability; IFA 3 - increase in the efficiency of cost management.

Figure 4 Integral level of digitalization of investment-innovative activity of trade business entities in the network IT-system of the Polissya and Western region zone of Ukraine under the vector-standard "Financial activity" 


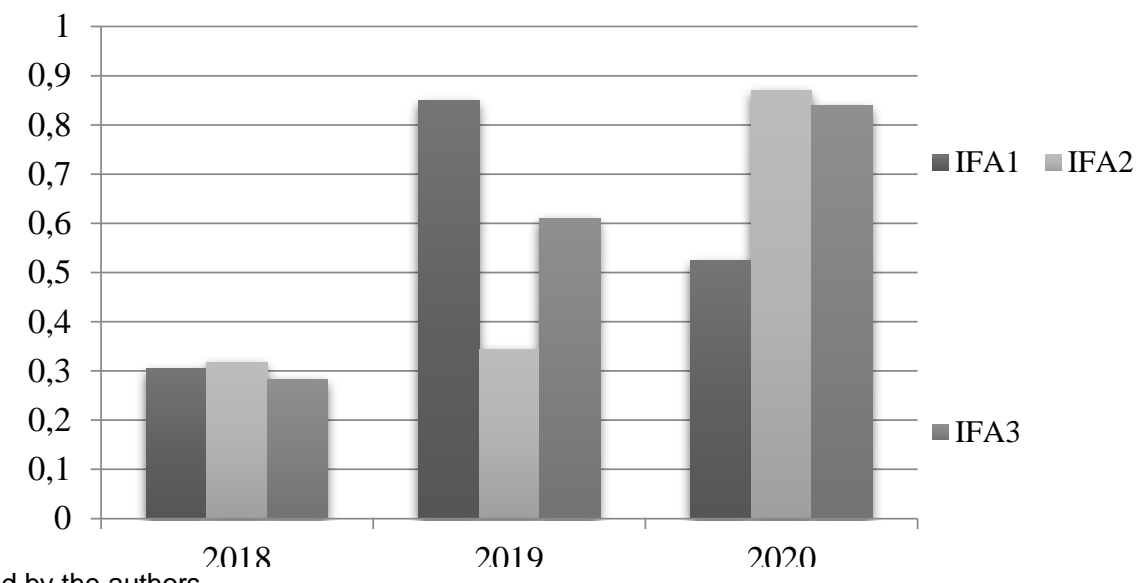

Source: calculated by the authors.

Note: IFA 1 - increase in the market value of trade entities; IFA $A_{2}$ growth of financial stability; IFA $A_{3}$ increase in the efficiency of cost management.

Figure 5 Integral level of digitalization of investment-innovative activity of trade business entities in the network IT-system of the Steppe zone of Ukraine under the vector-standard "Financial activity"

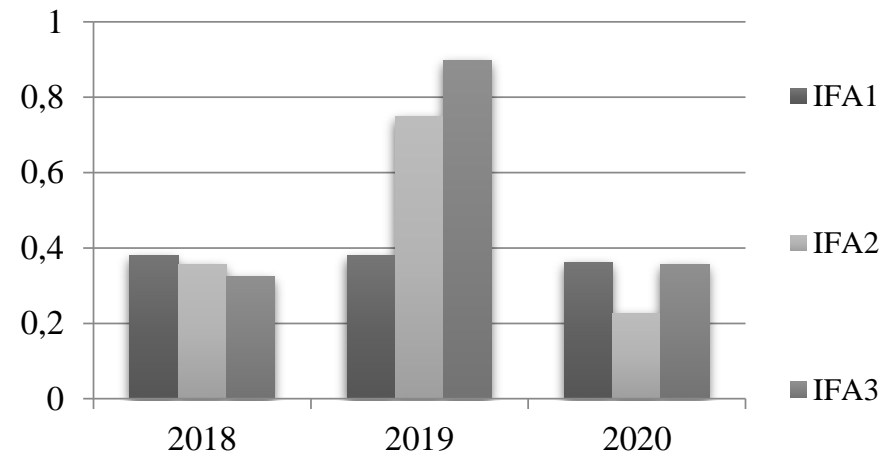

Source: calculated by the authors.

Note: IFA1 - increase in the market value of trade entities; IFA2 - growth of financial stability; IFA3 - increase in the efficiency of cost management.

Figure 6 Integral level of digitalization of investment-innovative activity of trade business entities in the network IT-system of the Forest-Steppe zone of Ukraine under the vector-standard "Counterparties"

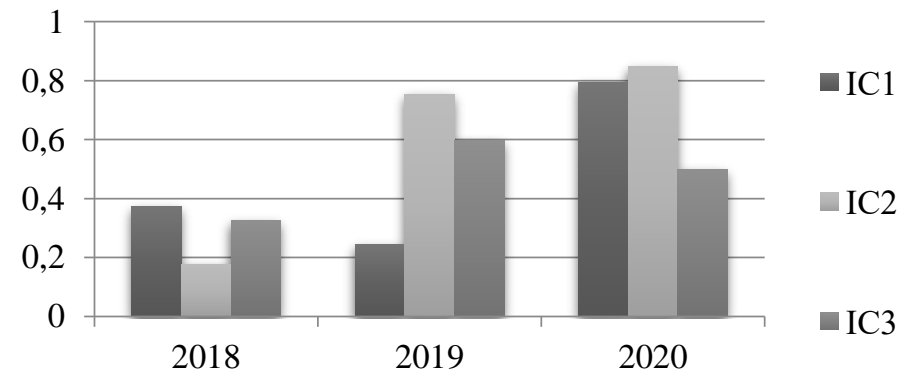

Source: calculated by the authors.

Note: IC1 - attracting new and retaining existing customers; IC2 - improving customer service; IC3 - improving partnerships.

Figure 7 Integral level of digitalization of investment-innovative activity of trade business entities in the network IT-system of the Polissya and Western region zone of Ukraine under the vector-standard "Counterparties"

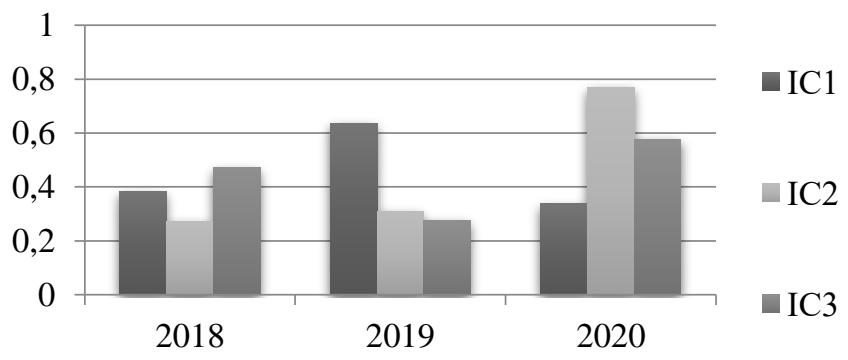

Source: calculated by the authors.

Note: IC1 - attracting new and retaining existing customers; IC2 - improving customer service; IC3 - improving partnerships. 
Figure 8 Integral level of digitalization of investment-innovative activity of trade business entities in the network IT-system of the Steppe zone of Ukraine under the vector-standard "Counterparties"

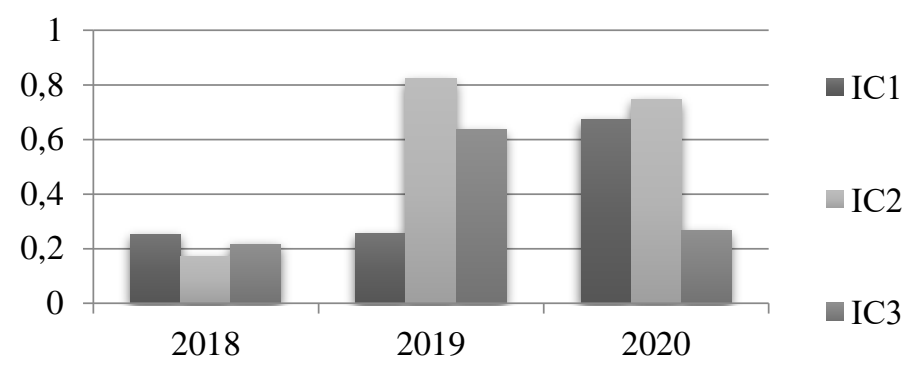

Source: calculated by the authors.

Note: IC1 - attracting new and retaining existing customers; IC2 - improving customer service; IC3 - improving partnerships.

Figure 9 Integral level of digitalization of investment-innovative activity of trade business entities in the network

IT-system of the Forest-Steppe zone of Ukraine under the vector-standard "Internal business processes"

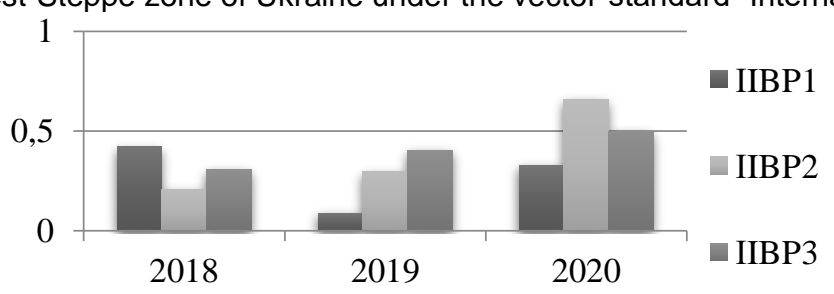

Source: calculated by the authors.

Note: IIBP1 - improving the organizational structure of management; IIBP2 - raising the level of organization of the trade and technological process; IIBP3 - increasing the level of informatization.

Figure 10 Integral level of digitalization of investment-innovative activity of trade business entities in the network IT-system of the Polissya and Western region zone of Ukraine under the vector-standard "Internal business processes"

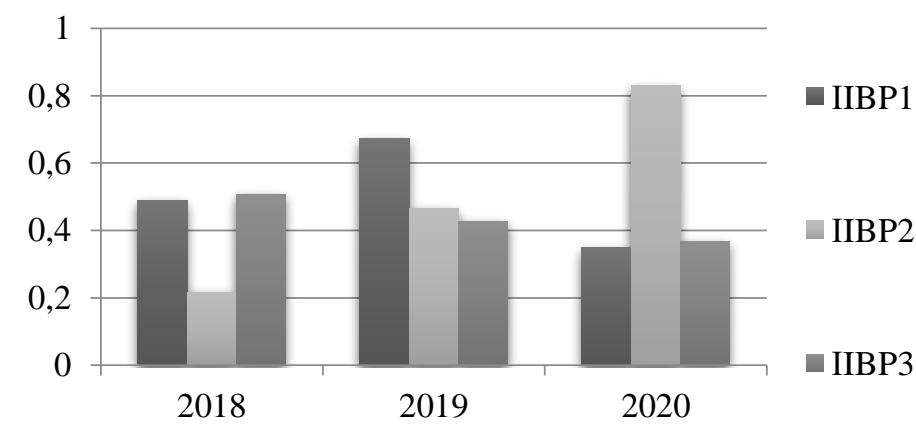

Source: calculated by the authors.

Note: IIBP1 - improving the organizational structure of management; IIBP2 - raising the level of organization of the trade and technological process; IIBP3 - increasing the level of informatization.

Figure 11 Integral level of digitalization of investment-innovative activity of trade business entities in the network IT-system of the Steppe zone of Ukraine under the vector-standard "Internal business processes"

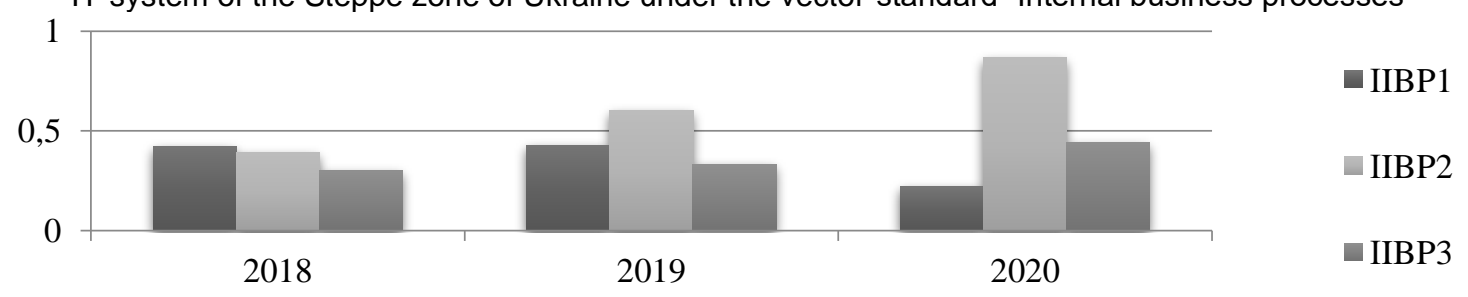

Source: calculated by the authors.

Note: IIBP1 - improving the organizational structure of management; IIBP2 - raising the level of organization of the trade and technological process; IIBP3 - increasing the level of informatization.

The subjects of the trade network in the zone of Polissya and the Western region provide a constant increase in the efficiency of cost management, as evidenced by the dynamics of the taxonomy ratio $\left(\mathrm{IFA}_{3}\right)$, the level of which increased in 2018-2020 from 0.283 to 0.839; in the Forest-Steppe and Steppe zones there was a reverse trend. According to the value of the integrated indicators of the block "Counterparties", the intensification of investment-innovative activities of trade entities provides a sufficient level of relationships with buyers and partners. Thus, the dynamics of the integrated 
indicator of attracting new and retaining existing customers indicates that the introduction of investment and innovation through the network of IT-systems in the studied areas of Ukraine contributes to achieving the goals of Digital-strategy for digitization of investment-innovative business development in the economy. In addition, there was a significant improvement in the level of customer service, i.e., in the Forest-Steppe zone the integrated indicator of improved customer service increased from 0.177 to 0.847 , in the Steppe zone - from 0.173 to 0.747 , and in the zone of Polissya and the Western region - from 0.273 to 0.768 . This became possible with modern forms of service, such as online stores, self-service checkouts, and express service. However, according to research, investmentinnovative activities of the trade entities in any of the studied areas of Ukraine have not helped to establish a steady trend of improving partnerships. The zone of Polissya and the Western region has the greatest value of the integrated indicator of the level of achievement of Digital-strategy in 2020, which is 0.103 points less than in 2018 and 0.076 points more than in its nearest competitor - ForestSteppe zone.

The studied level of integrated indicators of the block "Internal business processes" has significant differences in achieving the directions of Digital-strategy. Thus, in 2020, the intensification of investment-innovative activities of trade entities with a developed network of IT-system is characterized by the lowest value of the integrated indicator of the organizational management structure (Forest-Steppe - 0.328; Polissya and the Western region-0.348; Steppe -0.221) and the highest value of the integrated indicator of the level of organization of trade and technological process (Forest-Steppe - 0.660; Polissya and the Western region - 0.831; Steppe - 0.866). Update of trade and cash equipment, acquisition of modern information and technological programs explains the positive change in the integrated indicator of the level of organization of trade and technological process. In the studied areas of Ukraine, the level of informatization varies from 0.3 to 0.508 and is characterized, unfortunately, by high values of information technology consumption rates and low indicators of business digitalization, as well as the development of the Internet. Group integrated indicators of the zonal level of digitization of investment-innovative activities of trade entities in the network IT-system of Ukraine by the components of the BSI are presented in Figure 12-14.

Figure 12 Group integrated level of digitalization of investment-innovative activities of trade business entities in the network IT system of the Forest-Steppe zone of Ukraine according to the components of the BSI

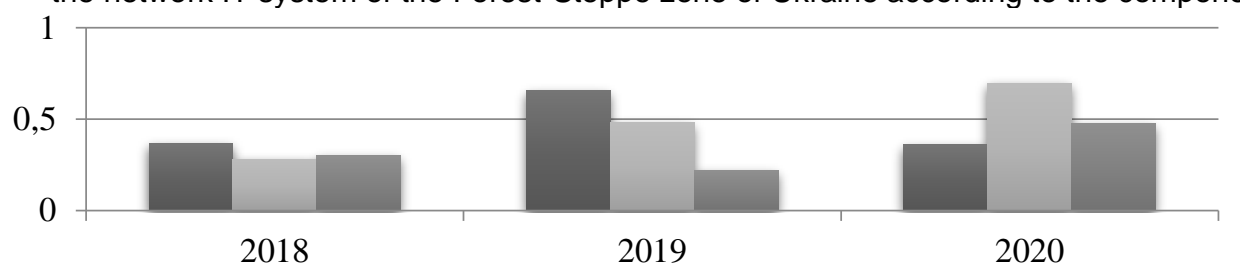

Financial
activity

Figure 13 Group integrated level of digitalization of investment-innovative activities of trade business entities in the network IT-system of the Polissya zone and the Western region of Ukraine according to the components of the BSI

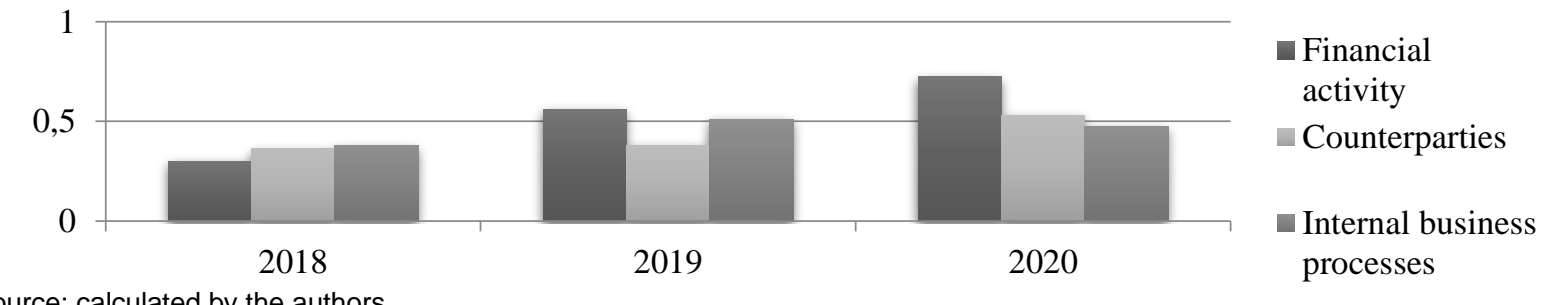

Source: calculated by the authors. 
Figure 14 Group integrated level of digitalization of investment-innovative activities of trade business entities in the network IT-system of the Steppe zone of Ukraine according to the components of the BSI

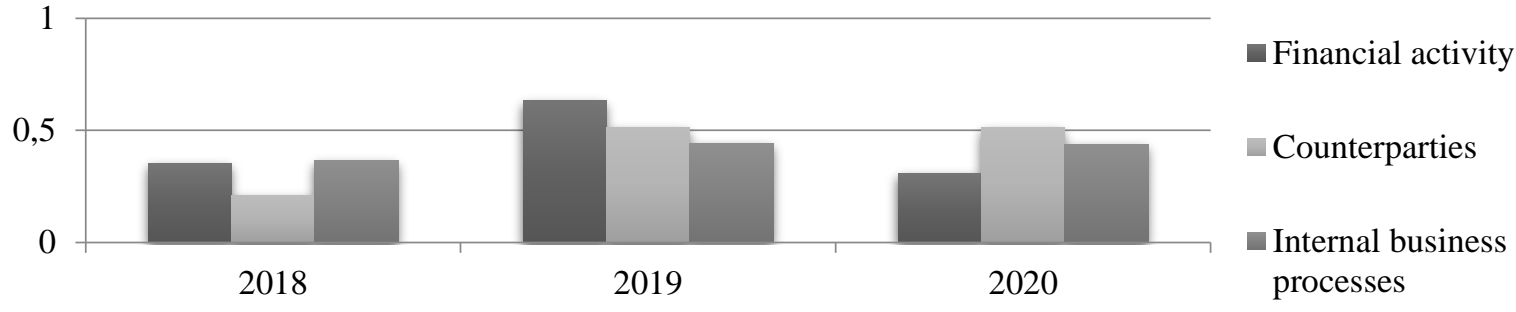

Source: calculated by the authors.

Thus, in 2020 in the Forest-Steppe zone of Ukraine the greatest value of the group integrated indicator is observed, i.e., the block "Counterparties" (IC $=0.696)$ has a positive impact on the intensification of investment-innovative activities of the trade business. The level of digitalization of investment-innovative activities of trade entities in the network IT system of the Polissya zone and the Western region of Ukraine is intensified under the positive influence of the factors of the block "Financial activity" (IFA = 0.726). In the Steppe zone of Ukraine, the factors of the "Counterparties" block (IC $=0.512$ ) have a positive impact on the activation of the level of the integrated indicator. The relative importance of each component that affects the zonal integrated level of digitization of investment-innovative activities of trade entities is determined using the method of analysis of hierarchies and expert evaluation, the results of which are presented in Figure 15.

Figure 15 Local priorities of the components of the zonal integrated level of digitalization of investment-innovative activities of trade entities in the network IT-system of Ukraine

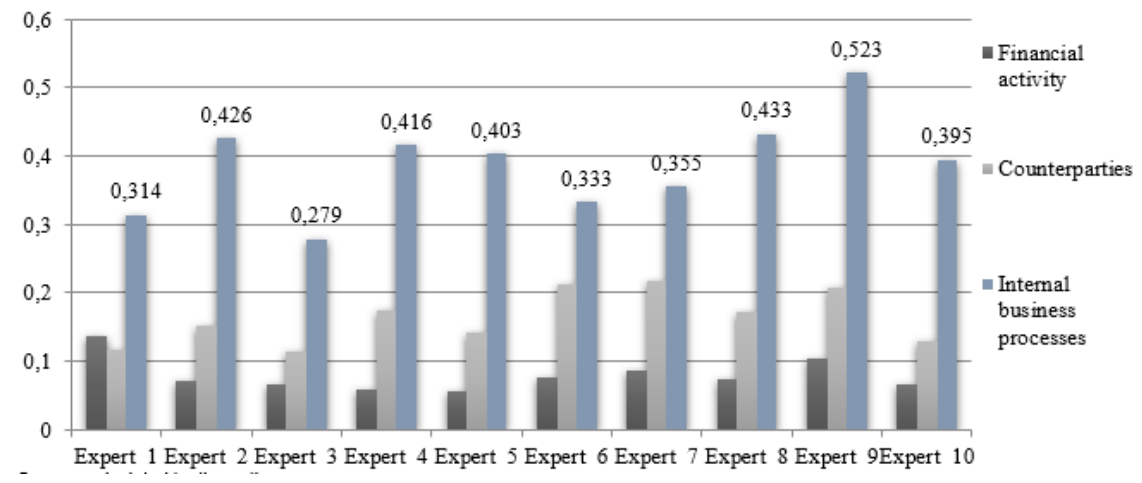

Source: calculated by the authors.

To summarize the estimates of experts, the geometric mean was used to calculate the matrix of pairwise comparisons for the components of the integrated indicator and their relative importance is presented in Figure 16. At the same time, the consistency of expert assessment of the importance of the components of the integrated indicator according to the consistency index is 0.021 and relative agreement is equal to 0.025 , the value of the indicator relative agreement does not exceed $10 \%$.

Figure 16 Activation of the zonal level of digitalization of investment-innovative activities of trade entities in the network IT system of Ukraine

Zones of digitalization of investment-innovation activity of trade business entities in the network IT-system of Ukraine

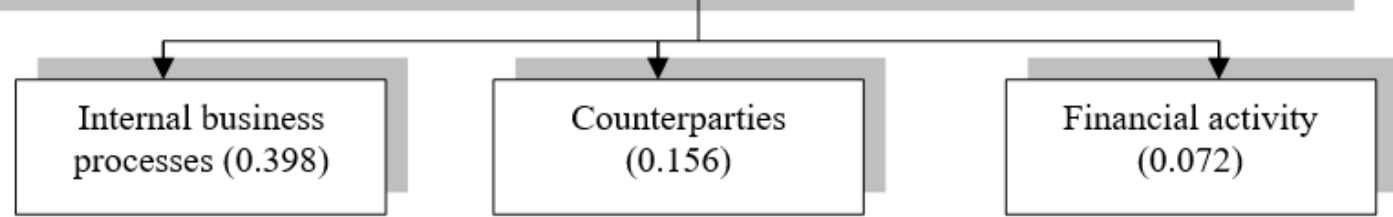

Source: calculated by the authors.

Thus, taking into account the results of calculations of group integrated indicators of the zonal level of digitalization of investment-innovative activities of trade entities in the network IT-system of 
Ukraine according to the components of the BSI, the overall integrated indicator for $2018-2020$ is determined (Figure 17).

Figure 17 General integrated zonal level of digitalization of investment-innovative activities of trade entities in the network IT-system of Ukraine

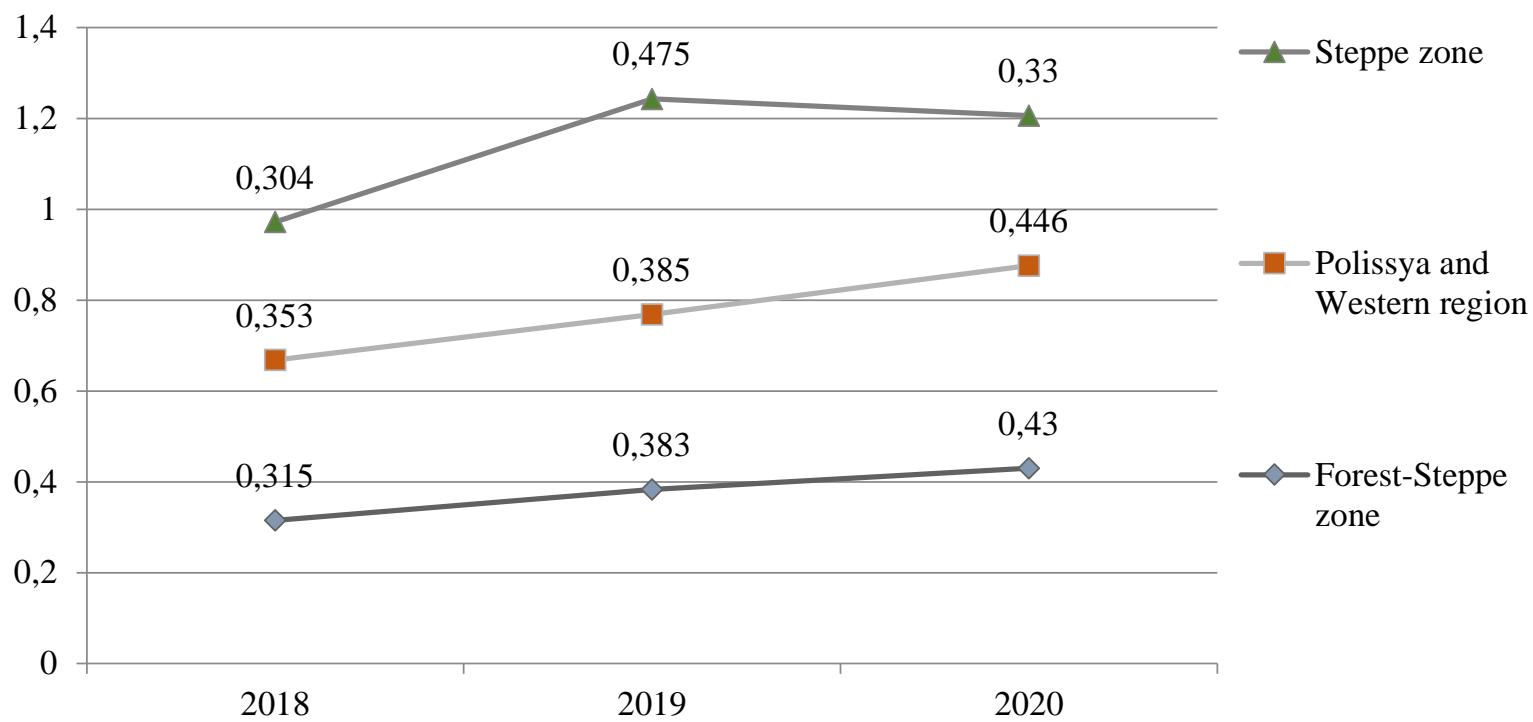

Source: calculated by the authors.

Analyzing the overall integrated indicator, it is necessary to note its gradual growth in the ForestSteppe zone and the Polissya zone and the Western region, but in the Steppe zone in 2020 its reduction is observed. To qualitatively assess the result, the Harrington verbal-numerical scale was used, which allowed identifying the studied areas of Ukraine by the criteria of activation of digitalization of investment-innovative activities of trade entities in the network IT system (Table 8). The results show that the zones of the Forest-Steppe, Polissya and the Western region have an average level of intensification of investment-innovative activities of trade entities.

Table 8 Activation of the zonal level of digitalization of investment-innovative activities of trade entities in the network IT system of Ukraine

\begin{tabular}{|l|c|c|c|}
\hline $\begin{array}{c}\text { Zones of digitalization of investment-innovation activity of } \\
\text { trade business entities in the network IT-system of Ukraine }\end{array}$ & 2018 & 2019 & 2020 \\
\hline Forest-Steppe zone & Low & Medium & Medium \\
\hline Polissya and Western region & Medium & Medium & Medium \\
\hline Steppe zone & Low & Medium & Low \\
\hline
\end{tabular}

Source: calculated by the authors.

Thus, the integrated indicator of the zonal level of digitization of investment-innovative activities of trade entities in the network IT system of Ukraine basically takes into account the diverse areas of Digital strategy and allows the selection of the most priority, in the context of balance between resource potential and opportunities (threats) of its external environment. The authors should note that the trade business can choose any direction of development, guided by the mission of investment and innovation and available tools to influence the processes. Accordingly, the digital transformation has the greatest potential, as it is a new prototype of economic reconstruction, implemented through the implementation of a flexible modular set of models and tools that are fully available for adaptation in traditional business systems (Digital single..., 2017; Mavlutova et al., 2021) (Figure 18).

Outsourcing helps to maintain this balance and increase the competitiveness of trade entities. The main reason for the decision to outsource part of business processes is the desire of business entities to consistently concentrate resources on innovation of their activities. It should be noted that the IToutsourcing market is aimed at servicing small and medium-sized businesses (mass IT-outsourcing market), as well as aimed at servicing the corporate segment (professional services market). The Ukrainian IT-outsourcing market demonstrates stable dynamics of economic development, while 
reducing the cost of material resources, which allows reducing the time of entrepreneurs and large trade businesses to negotiate with foreign contractors. Accordingly, the transition of the trading business to digitalization requires entities to spend more time online than to resolve business issues offline. This provides an increase in their competitiveness in the economy.

Figure 18 Model of digital business transformation

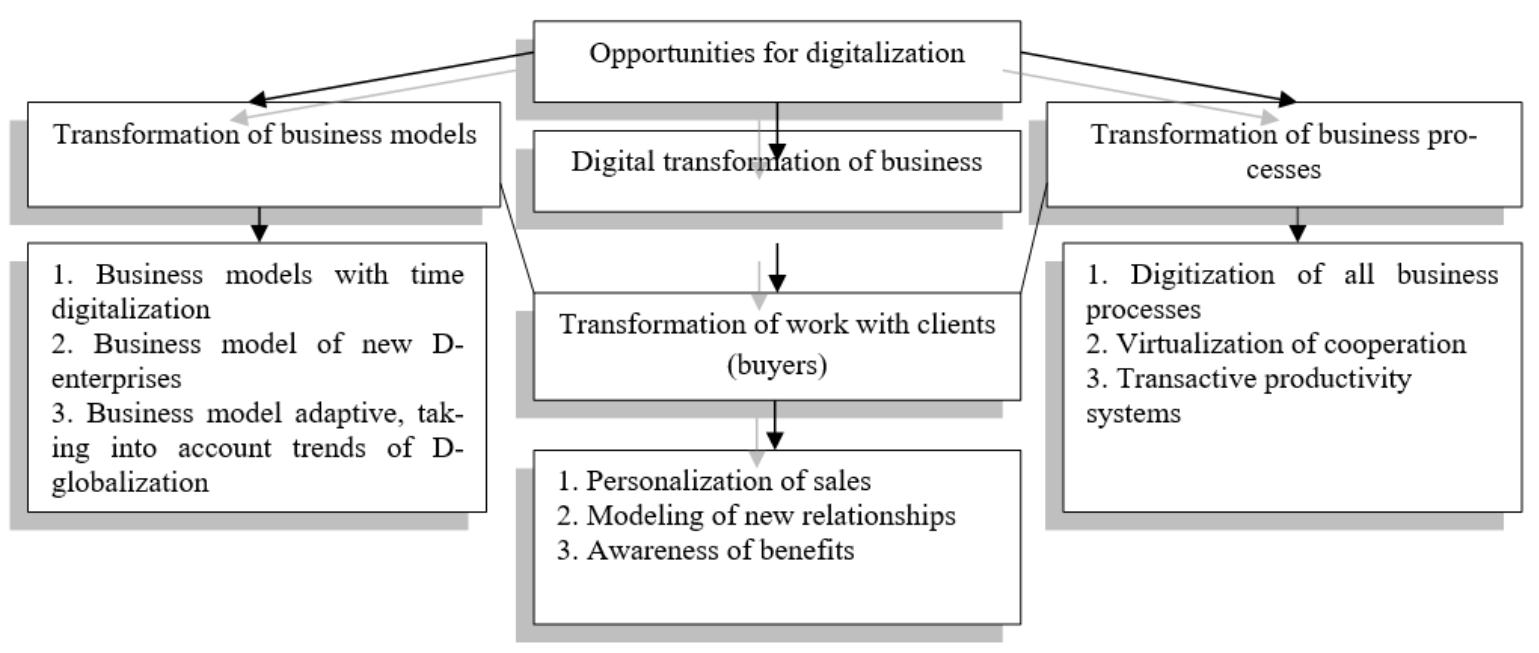

Source: calculated by the authors.

The research conducted by surveying respondents show that the most popular areas of IToutsourcing in Ukraine are the development of business applications and integration $-41.70 \%$, as well as outsourcing of IT infrastructure $-33.90 \%$ (Figure 19).

Figure 19 The most popular areas of IT-outsourcing in Ukraine

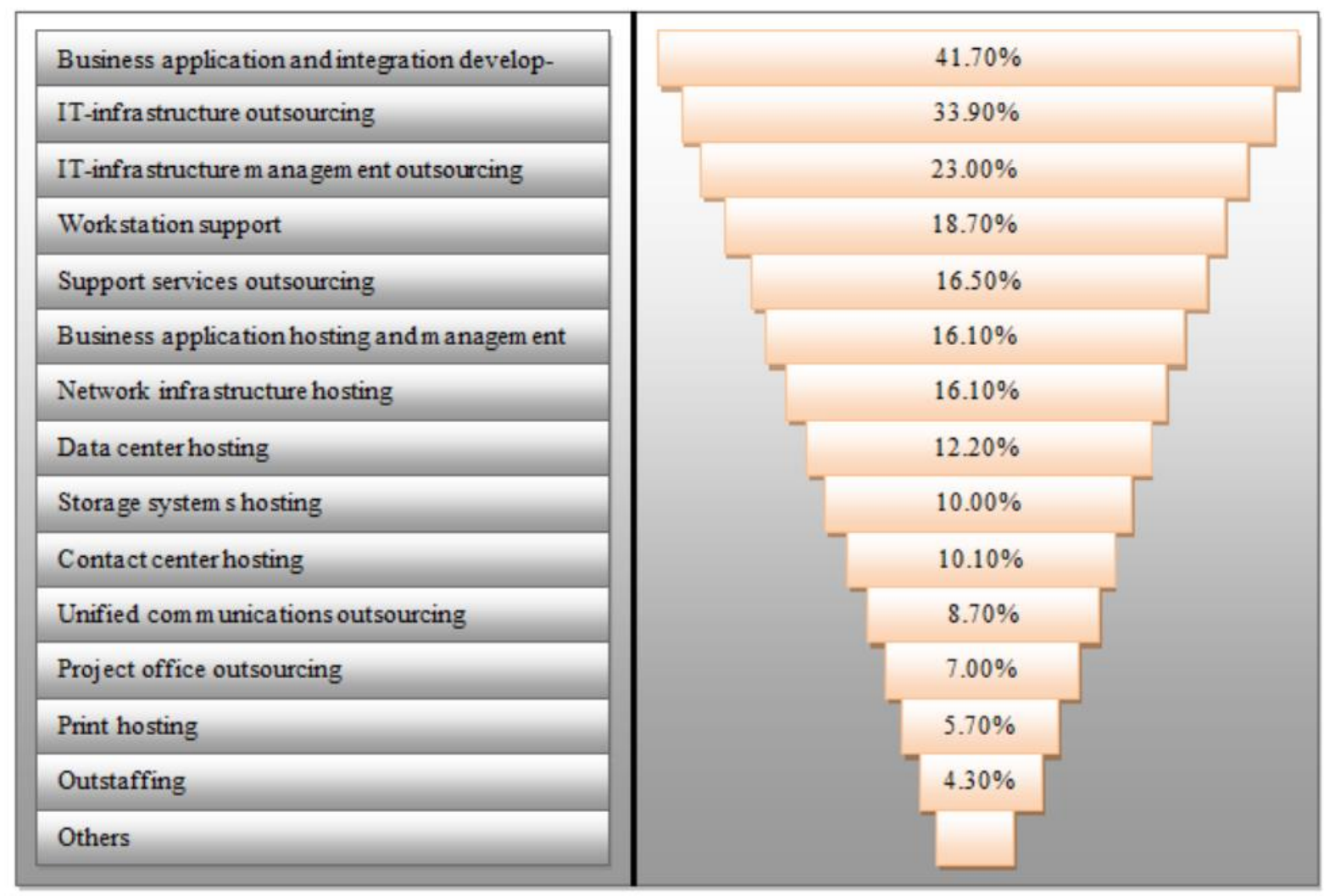

Source: authors' own research.

A comprehensive form of IT-outsourcing is a form of deeper involvement of partner companies' resources in the client's business processes, service and management of the entire IT-infrastructure, which is called strategic outsourcing. Its key difference from all other forms is that with this option of 
outsourcing it is possible not only to radically restructure business processes, but also to significantly improve all opportunities and prospects. All those trade enterprises that strive for stable business growth pass their way, but the introduction of information technology at all levels of trade entities is a prerequisite for comprehensive outsourcing. The difficulty of this path is that "it is impossible to take and implement technology" in any business process. This is a strong argument in favor of the fact that trade businesses should go the way to strategic outsourcing along with partners who understand the essence of the customer's business. In order to implement a system or technology to benefit commercial enterprises, it is necessary to fully understand where and how it will be used. This can be achieved only with a deep knowledge of technology, industry and business process.

\section{Conclusion}

Intangible factors of institutional nature (innovation culture) play an important role in outsourcing projects that affect such a risk-sensitive area as the information infrastructure of the business process. Its presence or absence, as well as the completeness of expression, largely determine the performance of the interaction of outsourcing partners. In addition, the following factors play an important role in building interaction: the cost of IT-outsourcing services, which are provided in accordance with clear and understandable to all project participants quality standards and are more economical; customer care (comprehensive, long-term and quality IT-outsourcing services should enable the customer to feel comfortable and at ease in all conditions - both in times of growth and in periods of stagnation, which increases the attractiveness of joint projects; reputation of partners and customers; range of outsourcing services (partners and customers appreciate the integrated interaction in the case when the support of their information infrastructure of the business process is provided by one outsourcing company).

Thus, the introduction of a system of continuous improvement of digitalization of investmentinnovative activities of trade businesses, aimed at comprehensively improving the quality of network IT system in the economy, not only optimizes business operations, but also increases cooperation in planning, organization, negotiating, concluding agreements with service partners, etc. Moreover, it contributes to the establishment of a certain strict control of costs at all stages of the value chain of business projects, as well as the improvement of methods of analysis, control over investment and innovation risks; use of a single standard - a tool that helps solve the problem of building an effective IT support system; creating a highly professional team. The introduction of IT outsourcing allows quickly updating and restarting business projects of any scale and in any area, in the interests of customers.

\section{References}

1. Arkolakis, C. (2018). Innovation and production in the global economy. American Economic Review, 8, 21-8.

2. Arthur, B.W. (1989). Competing technologies, increasing returns and lock in by historical events. Economic Journal, 99, 116-31.

3. Bochulia, T., Hrynko, P., \& Mukhina, M. (2018). Innovative trends of business development as an incentive to achieve progressive competitive advantages. European Cooperation. Scientifik Approaches and Applied Technologies, 3(34), 42-51.

4. Brandon, G. (2017). Can the blockchain scale? https://www.nsf.gov/funding/pgm_summ.jsp?pims_id=503286 [Accessed Feb 15, 2021].

5. Côté, S., \&Miners, C.T. (2006). Emotional intelligence, cognitive intelligence, and job performance. Administrative Science Quarterly, 51(1), 1-28.

6. Cox, D.R., \& Stuart, A. (1955). Quick sign tests for trend in location and dispersion. Biometrica, $42,80-95$.

7. Daum, J.H. (2002). Intangible assets. Bonn: Galileo Press GmbH.

8. Davenport, T.H. (1993). Process innovation: reengineering work through information technology. 
Boston: Harvard Business School Press.

9. Davymuk, S.A., Fedulova, L.I., \& Popadynets, N.M. (2016). Innovative development of enterprises in the field of trade: world trends and practice in Ukraine. Lviv: M.I. Dolishnoho Institute of Regional Studies.

10.Digital globalization: The new era of global flows (2016). www.mckinsey.com/businessfunctions/digital-mckinsey/our-insights/digital-globalization-the-new-era-ofglobal-flows [Accessed Feb 15, 2021].

11.Digital single market. Bringing down barriers to unlock online opportunities (2017). https://ec.europa.eu/commission/priorities/digital-single-market_en [Accessed Feb 15, 2021].

12.Drucker, P.F. (1995). Post-capitalist society. Oxford: Butterworth-Heinemann.

13.Foss, N., \& Saebi, T. (2018). Business models and business model innovation: Between wicked and paradigmatic problems. Long Range Planning, 1, 9-21.

14.Garber, P. (1996). Managing risks to financial markets from capital flows: The role of prudential regulation. International Journal of Economics, 1, 119-31.

15.Goleman, D. (1995). Emotional intelligence: Why it can matter more than IQ? New York: Bantam Books.

16. Hamel, G., \& Prahalad, C. (2005). Strategic intent. Harvard business review. https://hbr.org/2005/07/strategic-intent [Accessed Feb 15, 2021].

17. Hayek, F.A. (1948). Individualism and economic order. By Friedrich. Chicago: University of Chicago Press.

18. Hryhoruk, P.M. (2013). Theoretical and methodological principles of integrated evaluation of the effectiveness of marketing decisions. Economy: The Realities of Time, 3(8), 194-201.

19.Kulchytska, Kh.B., \& Predko, L.S. (2018). Application of the method of analysis of hierarchies when choosing a project in printing. Printing and Publishing, 1(75), 51-60.

20.Lane, N. (1999). Advancing the digital economy into the 21st century. Information Systems Frontiers, 1(3), 317-20.

21.Mavlutova, I., Volkova, T., Natrins, A., Spilbergs, A., Arefjevs, I., \& Miahkykh, I. (2021). Financial sector transformation in the era of digitalization. Estudios De Economia Aplicada, 38(4), 4055.

22.Oklander, M., Chukurna, O., Oklander, T., \& Yashkina, O. (2021). Methodical approach to calculating information value in pricing policy in supply chains. Estudios De Economia Aplicada, 38(4), 4009.

23.Rogers, E. (2002). Diffusion of innovations. New York: Free Press.

24.Saati, T. (1993). Decision-making. Hierarchy analysis method. Moscow: Radio and Communication.

25.Sorescu, A., Frambach, R.T., Singh, J., Rangaswamy, A., \& Bridges, C. (2011). Innovations in retail business models. Journal of Retailing, 87, S3-S16.

26.Sowa, J.F., \& Zachman, J.A. (1992). Extending and formalizing the framework for information system architecture. IBM Systems Journal, 31(3), 590-616.

27.Tapscott, D. (1996). The digital economy: promise and peril in the age of networked intelligence. New York: McGraw-Hill.

28.Vyshnevskyi, O., Stashkevych, I., Shubna, O., \& Barkova, S. (2021). Economic growth in the conditions of digitalization in the EU countries. Estudios De Economia Aplicada, 38(4), 4041.

29.Zachman, J.A. (1987). A framework for information system architecture. IBM System Journal, 26(3), 276-92.

30.Zhu, P. (2016). Digital agility: the rocky road from doing agile to being agile. Pennsauken: BookBaby. 